Sir,

\section{Ocular langerhans cell histiocytosis}

Langerhans cell histiocytosis ( $\mathrm{LCH}$ ) occurs mainly in childhood but is rarer in adults (1-2 per million). ${ }^{1}$ Many organs can be involved, most frequently bone, including orbit. We report a rare adult case of $\mathrm{LCH}$, with unusual ocular skin presentation and uveal tract involvement.

\section{Case report}

A 45-year-old man had a right medial canthal nodule for 5 weeks. He smoked and drank to excess. His right VA was 6/9, left VA was 6/12. Excision biopsy of the lesion showed a dermal cellular infiltrate composed of histiocytic cells and eosinophils. The histiocytes displayed irregular, cleaved nuclei and demonstrated strong immunoreactivity for CD68, S100, and CD1a (Figure 1). Necrobiosis or giant cells were not present and there was no infiltration of epidermis. This pattern and immunocytochemical profile excluded the main differential diagnoses of Hodgkin's and non-Hodgkin's lymphoma, mycosis fungoides, and inflammatory disorders such as xanthogranuloma. The CD1a-positivity confirmed Langerhans cell histiocytosis. He failed to attend for follow-up. Fifteen months later, he developed black visual field shadows. VAs were 6/12 bilaterally, $6 / 9$ on pinhole correction. Fundoscopy revealed bilateral posterior uveitis, vitritis, and retinal vasculitis, and a left chorioretinal lesion (Figure 2). Vasculitic and infective screens (autoantibodies including ANF, ANCA, rheumatoid factor, and blood and CSF infective screen)

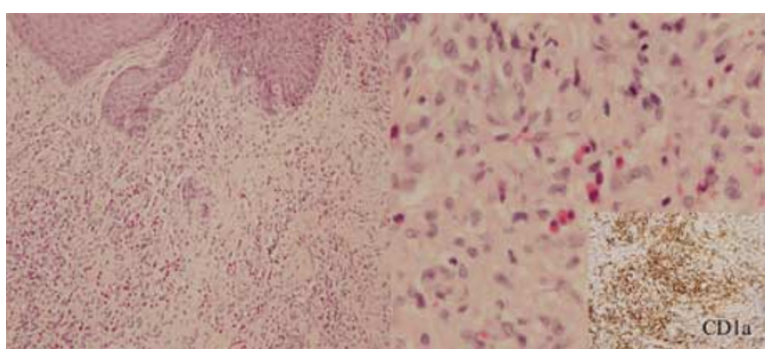

Figure 1 (a) Skin biopsy, showing infiltration of the dermis by S100-positive and CD1a-positive Langerhans cells. were negative. Chest radiology was normal. He was treated with $60 \mathrm{mg}$ prednisolone/day. Three weeks later, he developed a maculopapular rash involving face, neck, and hands. Skin biopsy showed $\mathrm{LCH}$.

His vision deteriorated (right VA 6/36, left VA 6/24) owing to bilateral anterior and posterior uveitis. Fundoscopy showed diffuse vasculitis, retinal haemorrhages, retinal oedema, and vitreous opacities, interpreted as uveitis masquerade syndrome. Repeat vasculitic screen was negative. CT of thorax, abdomen and pelvis was normal. Bone marrow aspirate and biopsy were negative for $\mathrm{LCH}$ or other co-existing malignancy.

He developed gait ataxia and distal hyperpathia. MRI brain showed increased signal intensity in both basal ganglia (Figure 3a) and medial recti. Meninges, cerebellum, and brainstem appeared normal.

Cerebrospinal fluid (CSF) examination showed LCH cells (Figure $3 b$ ). In view of the positive CSF, a vitreous aspirate was not performed. He received cranial radiation and intravenous and intrathecal chemotherapy. Vision improved (VA 6/9 bilaterally); speech and gait remained impaired. Repeat CSF examinations were negative for LCH cells. Two years later, bony lesions have not occurred.

\section{Comment}

Ocular presentation of adult LCH is exceptional. A solitary eyelid lesion, ${ }^{2}$ solitary choroidal $\mathrm{LCH}^{3}$ a limbal nodule ${ }^{4}$ and six chorioretinal LCH cases $^{5,6}$ are
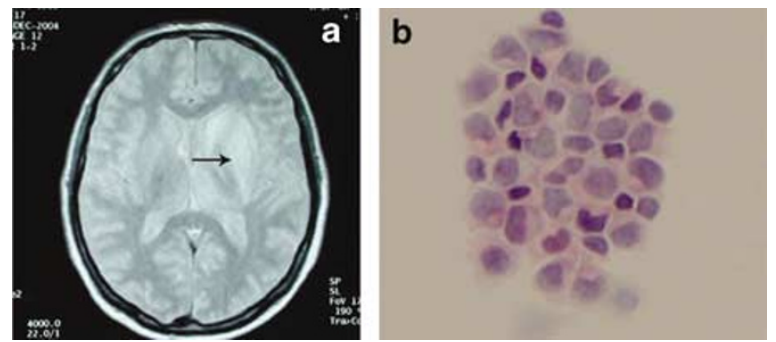

Figure 3 (a) MRI of brain with abnormal signal intensity in the basal ganglia. (b) CSF cytology showing Langerhans cells and eosinophils.
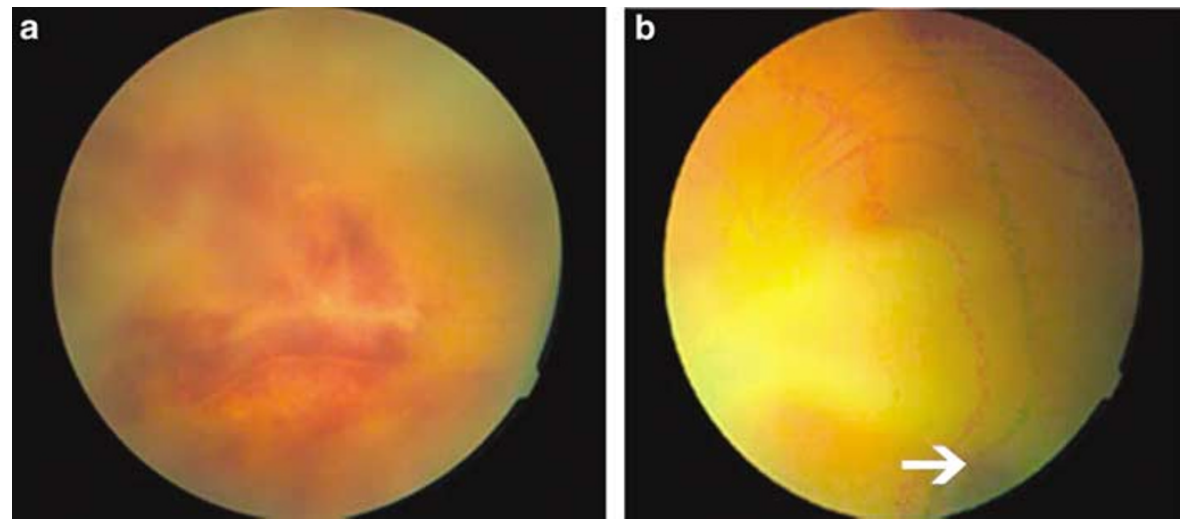

Figure 2 (a, b) Right and left fundi, showing a hazy view because of vitritis: there is vasculitis bilaterally and a left chorioretinal lesion (arrow). (a) Right fundus, (b) Left fundus. 
reported. To our knowledge, this is the first report of LCH causing uveitis masquerade syndrome. Only $1-4 \%$ of LCH patients develop intracerebral infiltration not extending from bone, usually with widespread disease and 5 years after diagnosis. ${ }^{7}$ Only 7 cases of positive CSF are reported, ${ }^{8}$ usually with meningeal infiltration. CSF involvement in this patient probably reflects brain infiltration, since meninges were normal on imaging. This case demonstrates unusual manifestations of $\mathrm{LCH}$ in the adult eye.

\section{Acknowledgements}

We thank Dr J Fitzgibbon and Dr J Hogan for reporting the skin biopsies and Dr D Ryder for the neuroradiology.

\section{References}

1 Singh A, Prieto VG, Czelusta A, McClain KL, Duvic M. Adult Langerhans cell histiocytosis limited to the skin. Dermatology 2003; 207(2): 157-161.

2 Warner TF, Reza Hafez G. Langerhans' cell tumour of the eyelid. J Cutan Pathol 1982; 9(6): 417-422.

3 Kim IT, Lee SM. Choroidal Langerhans cell histiocytosis. Acta Ophthalmol Scand 2000; 78(1): 97-100.

4 Saxena T, Kumar K, Sen S, Tandon R. Langerhans cell histiocytosis presenting as a limbal nodule in an adult patient. Am J Ophthalmol 2004; 138(3): 508-510.

5 Roca MJ, Gardella S, Teruel C, Lopez E. Disseminated Langerhans cell histiocytosis with pulmonary, bone and choroid involvement. Med Clin (Barc) 1994; 102(2): 79

6 MacCumber MW, Hoffman PN, Wand GS, Epstein JI, Beschorner WE, Green WR. Ophthalmic involvement in aggressive histiocytosis X. Ophthalmology 1990; 97(1): 22-27.

7 Grois N, Barkovich AJ, Rosenau W, Ablin AR. CNS disease associated with Langerhans cell histiocytosis. Am J Paediatr Haematol Oncol 1993; 15(2): 245-254.

8 Hamilton SR, Gupta PK, Marshall ME, Donovan PA, Wingard JR, Zaatari GS. Cerebrospinal fluid cytology in histiocytic proliferative disorders. Acta Cytol 1982; 26: 22-28.

N Bermingham¹, D Townley², S Fenton ${ }^{2}$ and C Keohane ${ }^{1}$

'Department of Neuropathology, Cork University

Hospital, Wilton, Cork, Ireland

${ }^{2}$ Department of Ophthalmology, Cork University

Hospital, Wilton, Cork, Ireland

E-mail: niamh.Birmingham@mailp.hse.ie

Eye (2007) 21, 1127-1128; doi:10.1038/sj.eye.6702898; published online 1 June 2007

\section{Sir,}

Reply to Ramamurthi and Rahman

The authors incorrectly cite Ian Mackie's paper (reference 41). Mackie did not advocate the induction of ptosis with botulinum toxin for the treatment of recurrent corneal erosions.

His method was to reduce the action of the orbital part of the orbicularis muscle by injecting it with botulinum toxin.

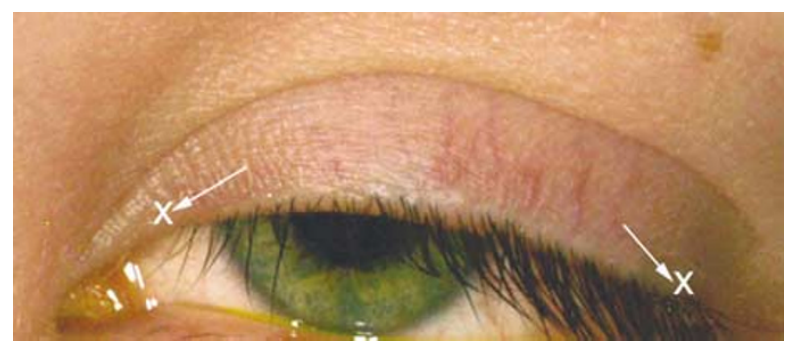

Figure 1 Injection sites for botulinum toxin are marked ' $X$ '. The syringe is orientated to point in the directions of the arrows.

Thirty-five years ago, Mackie had shown that contraction of the orbital portion of the orbicularis muscle stopped Bell's phenomenon. ${ }^{1}$ Normal blinking involves only the palpebral portion of the orbicularis muscle and is accompanied by Bell's phenomenon. He presumed that orbital orbicularis action prevented Bell's phenomenon during rapid eye movements in sleep and induced corneal erosion.

Using a modification of Mackie's method, in which I inject into the upper eyelid Riolan's muscle, I have successfully treated eight cases of recalcitrant recurrent corneal epithelial erosions without noticeably altering the eyelid position. The intention is to reduce horizontal tension in the lid, on the basis that shearing between the lid and the ocular surface in combination with overnight reduction in tear secretion, and thus lubrication, is contributory.

I make two injections, each of $4 \mathrm{IU}$ of Botox ${ }^{\mathrm{TM}}$ or $12 \mathrm{IU}$ of Dysport $^{\mathrm{TM}}$, just above the upper-lid margin near the medial and lateral canthi (Figure 1). The choice of injection site was inspired by Mackie's paper on Riolan's muscle. ${ }^{2}$

\section{References}

1 Mackie IA. Localised corneal drying in association with dellen, pterygia and related lesions. Trans Ophthalmic Soc UK 1971; XCL: 129-145.

2 Mackie IA. Riolans's muscle: action and indications for botulinum toxin injection. Eye 2000; 14: 347-352.

\section{CS Bailey}

99 Harley Street, London, UK E-mail: csbailey@mac.com

Eye (2007) 21, 1128; doi:10.1038/sj.eye.6702899; published online 15 June 2007

Sir, Intravitreal triamcinolone and bevacizumab combination therapy for macular edema due to central retinal vein occlusion refractory to either treatment alone

A review of the literature showed no published cases using a combination of intravitreal triamcinolone and anti-VEGF agents for macular edema due to central retinal vein occlusion (CRVO). We present a case 